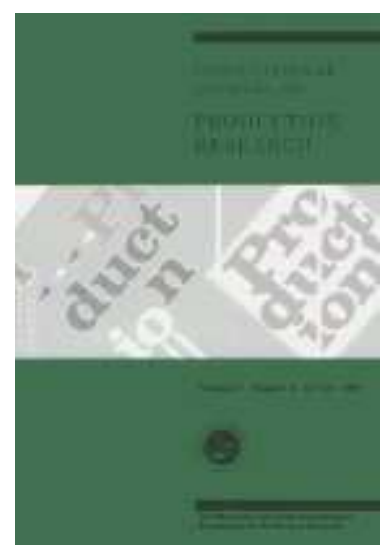

\title{
Formalization of process activity performance estimation approach using human competencies.
}

\begin{tabular}{|r|l|}
\hline Journal: & International Journal of Production Research \\
\hline Manuscript ID: & TPRS-2005-IJPR-0127.R1 \\
\hline Manuscript Type: & Original Manuscript \\
\hline $\begin{array}{r}\text { Date Submitted by the } \\
\text { Author: }\end{array}$ & $15-$ Dec-2005 \\
\hline Complete List of Authors: & $\begin{array}{l}\text { Bennour, Meziane; LIRMM, UMr. CNRS-UM2 5506 } \\
\text { Crestani, Didier; LIRMM, UMr. CNRS-UM2 5506 }\end{array}$ \\
\hline Keywords: & PERFORMANCE ANALYSIS, ENTERPRISE MODELLING \\
\hline Keywords (user): & competence model, performance estimation \\
\hline &
\end{tabular}

\section{s) ScholarONE" \\ Manuscript Central}




\title{
Formalization of process activity performance estimation approach
} using human competencies

\author{
M. Bennour, D. Crestani \\ Laboratoire d'Informatique Robotique et Microélectronique de Montpellier \\ 161 Rue Ada \\ 34392 Montpellier Cedex 5, France
}

\begin{abstract}
In a changing environment, the human factor is a key element to ensure the survival of an enterprise. It is hence necessary to model and analyse the enterprise processes with regard to both human and material resources. A French approach to process performance and its relation to the competence concept are presented. Several studies in which competence is integrated in the estimation of process performance are presented, and the method developed is described. It integrates individual and collective competencies to estimate the performance of an activity. This is first achieved in a specific case and, then generalized and formalized for different viewpoints. Finally, some new studies in which the proposed method was used are pointed out.
\end{abstract}

KEYWORDS: competence model, individual competence, collective competence, performance estimation. 


\section{Introduction}

As markets have become more versatile and saturated, and with changes in consumers' behaviour, industry has had to develop new production mechanisms. Flexibility, reactivity, innovation and anticipation are some of the parameters that have to be taken into account by industrial management. The human entity is required to address these parameters within the enterprise. Human cognitive and decision-making capacities are essential for assessing performance. Individual or collective human competencies-which were generally overlooked in the past - must nowadays be included in the analysis of enterprise processes.

The notion of performance, while highlighting its multidimentional nature, is presented in this article. Performance evaluation, linked to the definition of indicators, is mostly dependent on the resources and especially human resources involved. The evolution of the qualification concept is then discussed. This concept was applied quite early in French enterprises and has gradually evolved into the competence concept. Several studies are reviewed and analysed to characterise this concept and its relation to enterprise performance.

A method that was developed to integrate competencies in estimating the performance of process activities is described in detail, including the context of the study and an example to illustrate the work. The proposed method, which uses individual and collective competencies, is explained on the basis of a process activity example; then the methodology is generalized and formalized for different performance standpoints (temporal, financial and quality). Application of the method to estimate the performance of a process activity and to manage the human resources is then briefly discussed. The conclusion highlights its limitations and several ways that it could be enhanced.

\section{The performance concept}

\subsection{Classic model of performance}

An enterprise's performance is defined on the basis of its economic viability (its costeffectiveness) and different types of constraints (legal, social, etc.). This focus on the financial aspect overlooks the multidimensional character of performance (Bonnefous and Courtois 2001, Neel et al. 1995). This view of performance is warranted at the overall enterprise organization level, but the closer we get to the lower decision-making levels (operational levels), the relation between the value of the products and the cost of their production becomes less clear. The "operationalization" of the performance model is therefore highly intricate. The operational goals must include a measuring system with a set of performance indicators to quantify operational effectiveness and efficiency (Neel et al. 1995). In France, the AFGI (Association Française de Gestion Industrielle 1992) defines this concept as: "data quantification to measure the effectiveness of part of or a whole process relative to a norm, plan or goal that should be set and accepted as part of a global strategy". The performance indicator cannot be disassociated from 
the industrial goal, as characterized by the triplet-goal, measurement, action variables-. It allows the user to measure the performance level of a process, and is related to the employees' competencies involved in the implemented operations (Bonnefous and Courtois 2001).

The management accounting indicators used to assess Taylorian organizations were found to be limited (Johnson and Kaplan 1987, Berrah 1997). Until 1980, this management model did not show any significant improvements (Bourne 2003). With the evolution of the industrial environment, it is now criticized as the model is not adapted to reactive control (Haye and Garvin 1982) of new manufacturing organizations (Kaplan 1986). New approaches (Najar BenMahmoud 1996) have been proposed, some of which are based on assessments of performance from a technical-economic standpoint (Balanced SCorecard BSC (Kaplan and Norton 1992), ABC/ABM (Berliner and Brimson 1988), Kaizen, EcoGrai (Bitton 1990)), and others are based on assessments of performance using physical indicators such as Statistic Process Control (Gordon and Shaw-Taylor 1996), Total Productive Maintenance- TPM (Wireman 2004), etc.

The evolution of the performance has been made more complex. Initially, the performance was financials and productivity oriented now it measure other forms of performance at the level of the processes like the quality or the delays. The drawback of these methods is that they consider human entity as a material resources and overlook the impact of human competencies on performance.

\subsection{Qualification-Competence-Performance}

In France, the qualification model, which is still used in most enterprises, came from the "Ford" conception of industrial production. This model is thus analysed as a set of activities associated with various occupational positions. Paradeise and Lichtenberger (2001) announced that in the qualification model, individual capacities are conventionally identified by the position that recognizes the formal incorporation of knowledge and skills, by the initial or continued training and by seniority that validates the irreversible knowledge and know-how acquired from experience. The model is based on a stable relationship between individual skills, seniority and work positions, and allows minimum salaries to be set mechanically (Paradeise and Lichtenberger 2001). Its legitimacy relies on the fact that it is a product of collective negociations (Donnadieu and Denimal 1993). In the 1970s, the introduction of classifying criteria enabled recognition of a professional competence beyond qualification for an available position (Le Boterf 1994), then new criteria to evaluate the latter emerged. Autonomy, responsability and relational traits have been added to traditional criteria such as required competencies (training, experience) and job complexity (Machbach 1999). A new competence model is currently being developed (Zarifian 2001). 
Unlike the qualification model, each worker is locally classified within a set of interdependencies, where his performance is linked to that of a collective set involved in the resolution of a given problem. Hence, the production cannot be analyzed as a sum of independent activities that meet the requirements associated with predefined occupational positions. This new approach to industrial management thus breaks the traditional hierarchy and relies on competencies that are visible only in action. This approach is based on the premise that the employee's and organization's competencies evolve side by side and become the foundation of the enterprise's performance (Paradeise and Lichtenberger 2001). The notion of individual as well as collective competence requires consideration of the human entity in industrial processes.

\subsection{Competence : a multifaceted concept}

The competence concept is multifaceted and has been given numerous definitions. For example, De Montmollin (De Montmollin 1994) defined it as a set of mental structures containing all data necessary for an operator to carry out his task (learned knowledge and acquired knowledge by experience), as well as the applications required to solve a given problem. The French employers' organisation MEDEF (Medef 1998) defines "professional competence" as a combination of knowledge, know-how, experience and behaviour exercised in a particuliar context. By this definition, the competence notion is also extended to individual behaviour.

In the industrial domain, the concept is generally defined as a combination of knowledge (theoretical, contextual and procedural), know-how (practical and implemented in empirical manners) and behaviours (attitudes and relational or cognitive behaviours) (Boucher et al. 2003b, Boucher et al. 2003c, Boucher et al. 1999, Harzallah 2000, Harzallah and Vernadat 1999, Bonjour et al. 2002, Dulmet et al. 2001). This competence concept can be broken down into individual and collective competencies, with the latter being a coordinated and useful combination of individual competencies (Mudrak 1989, Hinds et al. 2000, Bonjour et al. 2002, Dulmet et al. 2001).

Hence, the competence concept has several different forms, which makes it hard for researchers to grasp. There is no universally accepted definition of this concept. However, this concept involves cognitive capacities that cannot be replaced, so the human entity is an essential component in the performance of the enterprise.

\subsection{Human resources : a performance vector}

The relation between the human entity and industrial performance has been underlined in numerous scientific fields. In economics, since the 19th century, the theory of human capital (Say 1821, Schultz 1961, Ehrlich 1990, Teixeira 2002, Becker 1992) has highlighted the importance of training on performance, but some authors postulate that this hypothetical correlation is not 
clearly proven (Fallon 1987, Maglen 1990). Soft sciences are focused on human behaviour. Some studies have assessed the relation between performance and the human entity through individual (Kolbe 1994), collective (Bullard et al. 1995, Dejoux 2001, Dejoux and Dherment 2000) and environmental (Johnston 1998, Wimmer 2000) dimensions. Lindgren (Lindgren 2001) stated that the success, survival, and competitive advantage of an enterprise depend on the competencies of its members, and how these are used. These disciplines thus clearly identify the human resource as an enterprise performance vector. Management of training, the enterprise environment and collective dimensions are parameters that should be taken into account to obtain a macroscopic representation of the performance of an enterprise.

Unlike the soft sciences, the industrial domain is not naturally focused on the human entity. However, it cannot overlook this parameter, and must strive to find an explicit way for its inclusion. This requires is more acute around research on scheduling and human resource allocation to processes.

Several studies have shown the importance of human resource management on the control of an enterprise's performance (Guérin et al. 1992, Ewan and Sackett 1998), but very few have explicitly taken this aspect into account (El Mhamedi 1990, Franchini et al. 2001, Tchommo et al. 2003), focusing instead on material resources.

Most scheduling work only includes the human resource in terms of availability and capacities (Gronalt and Harlt 2003, Grabot and Letouzy 2000, Croci et al. 2000, Billionnet 1999, Bhaskar and Srinivasan 1997, Lee and Vairaktarakis 1997). The human factor is identified but only assimilated as a material resource.

However, with the aim of implementing an allocation policy, some researchers have tried to model the impact of the human entity on the execution of an activity and the performance of a process. For example (Bobrowski and Park 1991, Boucher et al. 1995) consider that the manufacturing time depends on the operators' effectiveness. The influence of the operator training capacity is specifically taken into account to improve an organization's productivity (Nembhard 2001) or operating time (Arditi et al. 2001, Mosheiov 2001, Eckstein and Rohleder 1998).

In other studies, more complex models have been developed to individually characterize the human entity and its competencies. For example, Norman (Norman et al. 2002) considers that the total process performance (productivity, cost) is the result of adding the performance of all operators involved in its execution. He uses a multilevel competence model where competencies are evaluated in a deterministic way and participate in the execution of an enterprise's training plans. Pichot (Pichot 2001), in a scheduling study, focused on the total duration of work. To 
describe the human entity, she adopted the competence model (knowledge, know-how, and behaviour) developed by Harzallah (Harzallah 2000, Harzallah and Vernadat 1999). Franchini (Franchini 2000, Franchini et al. 2001) used the main competence concept to characterize operators on the basis of a tree-like model involving a set of criteria (experience, technicality, autonomy, evolution and relational). Competence needs are then identified to minimize worker allocation costs, while also efficiently adjusting the workload.

Aski (Askin et al. 2001) proposes a model derived from the soft sciences to describe the human resource. He integrates psychological, organisational and technical factors, while exploiting some personality traits that he considers to be valid indicators of work performance (Kolbe 1994).

Lastly, some researchers have sought to integrate the collective dimension necessary for constitution of autonomous production groups. To boost process productivity, Jia (Jia 1998) distinguishes business competencies (knowlege and know-how) that are based on the identification of a set of professional levels of transversal competencies (know-how, cognitive) through which the collective dimension emerges. El Mhamedi (El Mhamedi 1990) takes the collective work impact into account by defining a "cooperation" criterion, which highlights the best group distributions to enhance performance.

Other studies in the industry have tried to formalize the relation between competence and performance. These studies assess performance at the enterprise process level, while focusing mostly on the temporal dimension. However, few studies have explicitly acknowledged the relation between competence and performance. There is a lack of formalism in this relation. Some models with various degrees of granularity have been developed to specify this relation. Some just recognize the existence of workers in the enterprise. Others have sought to model their influence, while recognizing the importance of their training. The specific nature of the human entity and its multiple cognitive and training capacities have prompted researchers to develop the competence concept. However, besides this individual personality facet, his unique relational faculties have induced some researchers to introduce a collective dimension. Unfortunately, very few studies have investigated this complexity in the human resource model. The lack interdesciplinarity of the adopted methods, and generally their empirical nature, should be pointed out. The approaches developed generally overlook the collective work dimension and the dynamic of competencies.

Now, after demonstrating the importance of the relation between the human entity and performance, a study carried out with an industrial partner on the competence concept and its influence on an enterprise's process performance are presented. Several features of the abovementioned studies are reviewed from various standpoints. However, the goal is, first, to explicitly integrate the impact of knowledge, know-how and behaviours on process performance and, 
secondly, to integrate the dynamic of competencies.

\section{Work setting}

This research was conducted within the framework of a contract between the Merlin Gerin Alès factory and two laboratories LGI $2 \mathrm{P}^{1}$ and LIRMM. The goal was to define-based on the industrial partner's experience - a method to estimate the performance of enterprise processes while taking the impact of the human entity into account.

\subsection{Performance estimate principle}

Based on the concept developed by Covès (Covès et al. 2000, Covès 2000), and on the observations of our industrial partner, the hypothesis underlying our analysis is that it is possible to quantitatively evaluate the influence of human competencies on process performances (quality, cost, delays, etc.). The study of competencies involved a set of interviews with the industrial expert and was based on criteria used by the expert to characterize process activities, and evaluate associated occupational positions (Merlin 1997).

The developed method supposes that any activity is characterized, from each standpoint, by nominal performance. When carrying out activities, the influence of human resources on the performance assessment specifically takes the impact of the human competencies into account (Figure 1). These will then modulate (i.e. increase or reduce) the nominal performance of an activity, according to laws which have been elaborated with the industrial expert.

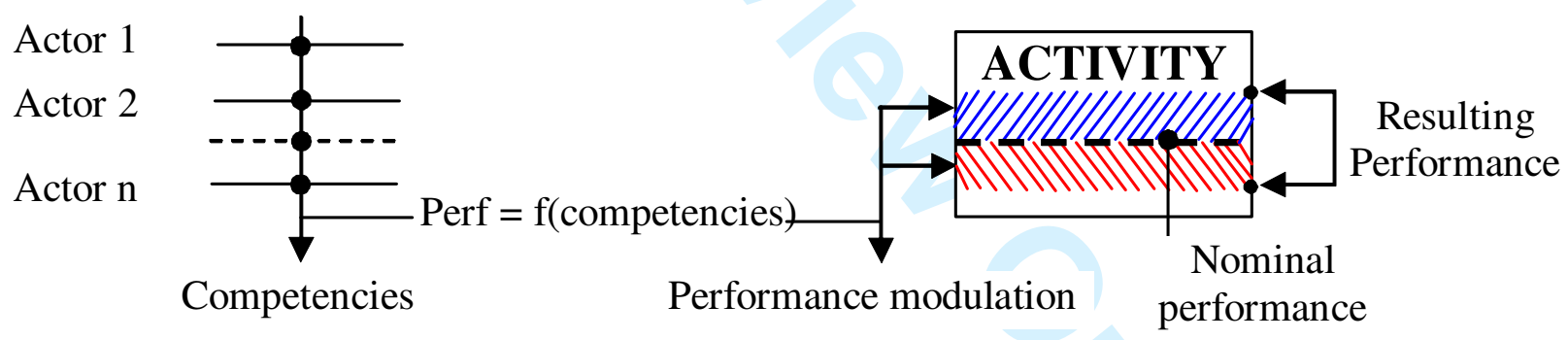

Figure 1 : From competencies to performance

One process of the partner's enterprise is used to illustrate the mechanism of performance modulation of an activity (Figure 2).

\subsection{The process example}

The method for integration of competencies in the performance calculation is illustrated on the

\footnotetext{
${ }^{1}$ Laboratoire de Génie Informatique et d'Ingénierie de Production
} 
basis of one process of the Merlin Gerin enterprise, termed the "production authorisation process" (PAP) (Figure 2). The goal of this process is to authorize, or not, the production of a new industrial product. This process, presented in Figure 2, is broken down into three activities (A1, A2, and A3), with the actors belonging to the technical team (that builds a working prototype of a product) or the production team (that produces the marketable product). A series of tests for the product are then defined during A1. These tests are then carried out in activity A2. Depending on the test results, necessary corrective actions are carried out prior to compliance authorisation or a production order is generated. The production order is then examined during activity A3 for a final decision.

In this process, individual and collective competencies are taken into account in calculating the temporal performance (duration) of the A2 activity.

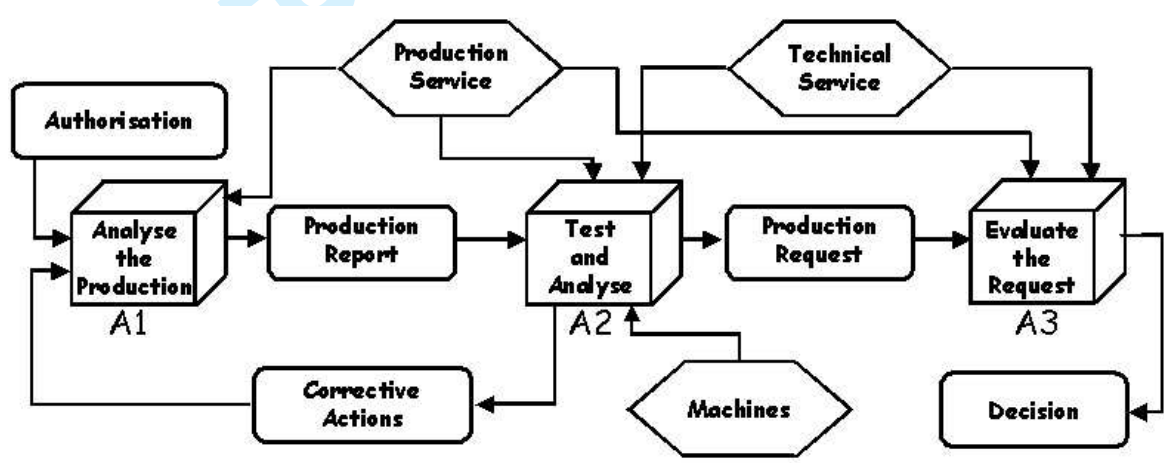

Figure 2 : The production authorisation process (PMP)

After the test process is selected, the competence model, upon which the performance assessment method is based, is described.

\section{The competence model}

Here the use of the competence concept for enterprise process modelling is presented.

\subsection{Activity, task, resource and competence}

The competence concept is tied both to the task and the human resources. The task is linked to its associated technical and human resources. These are termed «actors », which can be broken down into a set of individuals. The activity is the implementation of one or more tasks by one or several actors. This way of considering the different activity, human resource and competence factors is very close to that developed in (Amice 1993, Jia 1998, Poucel and Gourc 2002).

This competence concept is multifaceted since it considers knowledge, know-how and behaviour. It is also a multilevel concept since it can be either individual or collective. The activity is characterized by a set of required competencies necessary for its implementation. Human 
resources can have, to various degrees, a set of acquired competencies. These evolve with time as a function of the professional activity (know-how), applied training plans (behaviour, motivation) and individual capacities. In some situations, in the presence of other employees, the collective dimension of work is taken into account when integrating the relationship (behaviour) of the members of a team.

Now that the competence concept has been specified, the problem of its classification and influence on the implementation of a given activity is now presented.

\subsection{Main required competencies : factorization}

Each business domain (BM) involved in carrying out an activity necessitates a set of required competencies for its implementation. Harzallah (Harzallah 2000) highlighted the broad range of knowledge that has to be taken into account to finely characterize a competence. As noted by Franchini (Franchini 2000), individuals are characterized by their main competencies as a means of limiting the number of competencies to take into account. These main competencies are grouped into two classes. First, a set of individual main competencies (MC_I) relative to the human entity and considered independently of each other and, secondly, the collective main competencies (MC_C) that characterize the organization of human relations between the different individuals and the set of occupational positions involved. The latter cover the collective dimension of labor for a group of employees. The main competencies considered are shown in Table 1. This table shows also the existing relations with criteria used by Merlin Gerin enterprise (Merlin Gerin, 1997) to evaluate the employees.

\begin{tabular}{|l|l|l|}
\hline Type MP & \multicolumn{1}{|c|}{ Name } & \multicolumn{1}{c|}{ Criterion } \\
\hline MC_I & Technicality & To realise \\
\hline & Decision making & To decide - to supervise - to manage \\
\hline & Autonomy & To undertake \\
\hline & Innovation & To create \\
\hline MC_C & Management & To negociate - to organize- to animate \\
\hline & Relational & To communicate - to cooperate \\
\hline
\end{tabular}

Table 1 : Main competencies

Once the main competencies and business domains have been selected for a given activity, weighted factors are allocated for their relative contribution to the performance estimation. Values for these weight factors are determined, as in several studies (Jia 1998, Franchini et al. 2001), using a multicriteria method. Main competencies are described in a hierarchy by a treelike structure that permits evaluation of associated weight factors on the basis of information provided by the experts and using the analytical hierarchy process (AHP) method (Saaty 1980) for the multicriteria evaluation. Collective competencies are only defined by their involvement in the implementation of the activity. 
To facilitate the understanding of the developed approach, the following is focused on the A2 activity of the PAP process. This activity depends on two business domains, i.e. the production service (BD_P), and the technical service (BD_T). Table 2 highlights the main competencies involved in this activity. The weight factors affecting each business domain and each individual main competence are symbolically shown. Note that $T B D_{-} P$ is set at 1 because the production service is here dependent on only one competence, i.e. technicality.

\begin{tabular}{|c|c|c|}
\hline Business Domains & Production Domain BD_P & Technical Domain BD_T \\
\hline Technicality & TBD_P & TBD_T \\
\hline Decision making & 0 & DBD_T \\
\hline Autonomy & 0 & 0 \\
\hline Innovation & 0 & 0 \\
\hline Management & no & no \\
\hline Relational & yes & yes \\
\hline Number of individuals & 1 & 3 \\
\hline BD weightings & PBD_P & PBD_T \\
\hline
\end{tabular}

Table 2: Main competencies considered for the A2 activity of the PAP process

The dataset shown in Table 2 is the result of the audit and interviews with the enterprise experts who best know the studied process. Note that $P B D_{-} P$ and $P B D_{-} T$ are the weights of the production and technical business domains, respectively.

An activity is also characterized by nominal performance (cost, quality, duration). The A2 activity thus has a nominal duration $T_{N O M}$, a nominal financial cost $F_{N O M}$ and a nominal quality $Q_{N O M}$.

Once the relative importance of the business domains and the required main competencies have been identified, the relation between the employees' acquired competencies and the activity performance is defined.

\subsection{Relation of acquired individual competencies to performance}

According to (Harzallah 2000), individuals' competencies are characterized by a set of knowledge, know-how and behaviour. The latter, in the developed approach, influence the main competencies. Their impact is modeled using empirical and good sense laws (histogram, continuous function by section, etc.) established with the industrial partner. These allow, for a given activity context, evaluation of percentage of modulation of the nominal performance for a given main competence. The characteristics of these laws depend on the activities in which they are involved.

For example, the main competence technicality can be linked to the duration of an activity on the graph in Figure 3 that was empirically drawn up with the industrial expert. The observed 
coefficients of modulation evolve with the individual's experience (and hence his degree of expertise). A novice would raise the duration while an expert would reduce it. For a given training, a knowledge and eventually a know-how can appear. Individuals' motivation (behaviour) can result in a local modification in the slope of the graph.

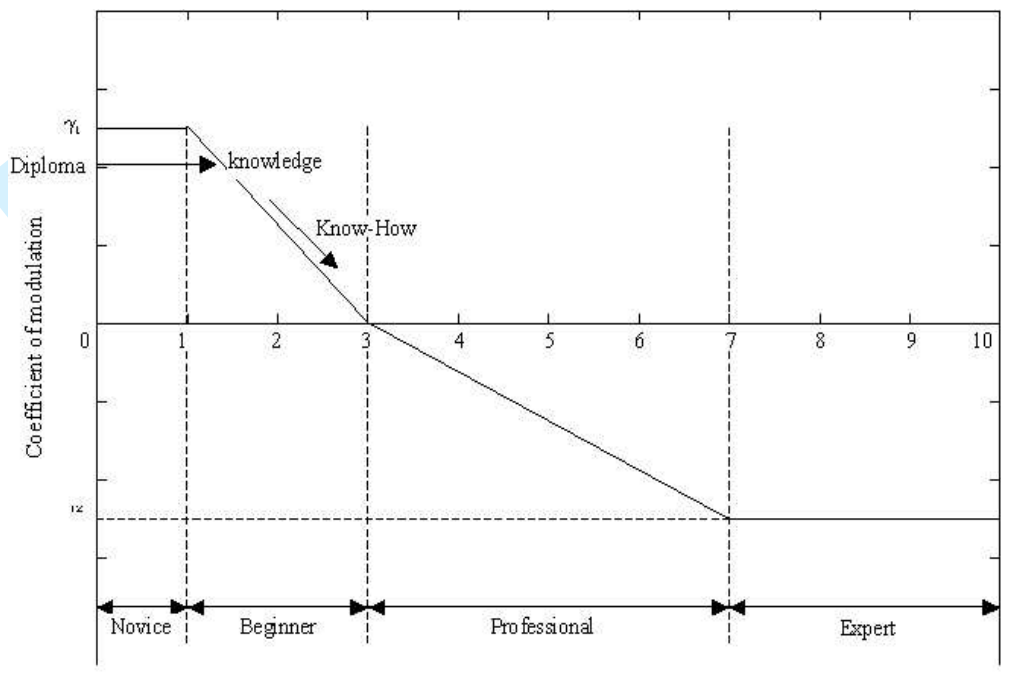

Experience (Years)

Figure 3: Modulation coefficient and MC_I technicality

In the same way, a histogram (Figure 4) to evaluate an individual's capacity to decide (main competence decision making) in a given context is used. For example, an individual with administrative background (director) is not adapted for a technical task. However, an engineer in a technical context is more suited to taking decisions. In some cases, experience can override the previous rule, whereby a technician with experience may be preferred over an engineer that has none.

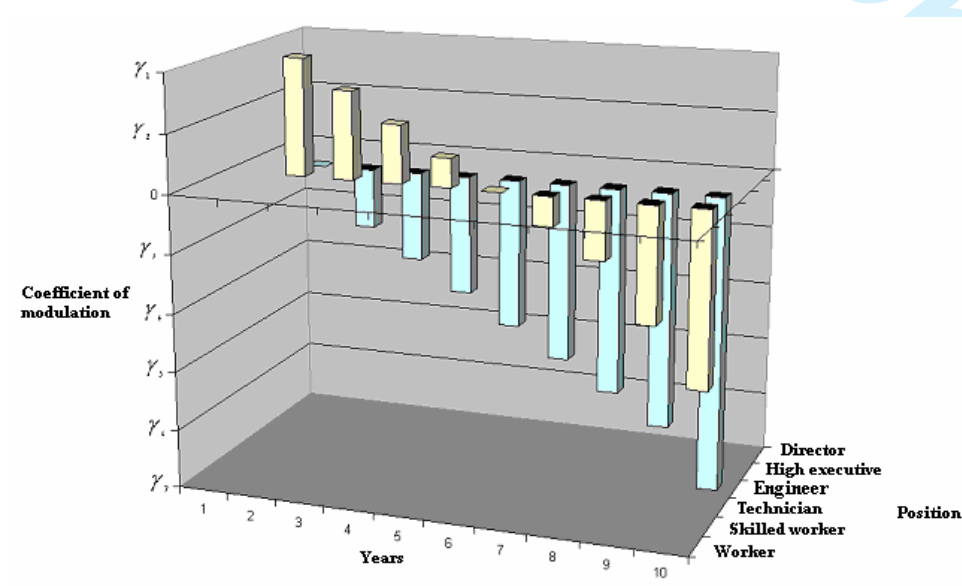

Figure 4 : Modulation coefficient and MC_I decision making 
There is a very close relation between behaviour and the relational capacities of individuals (relational MC_C). For the latter, there are six levels, ranging from "very bad" to "excellent" (Figure 4); these are used to define an individual's behaviour in a group.

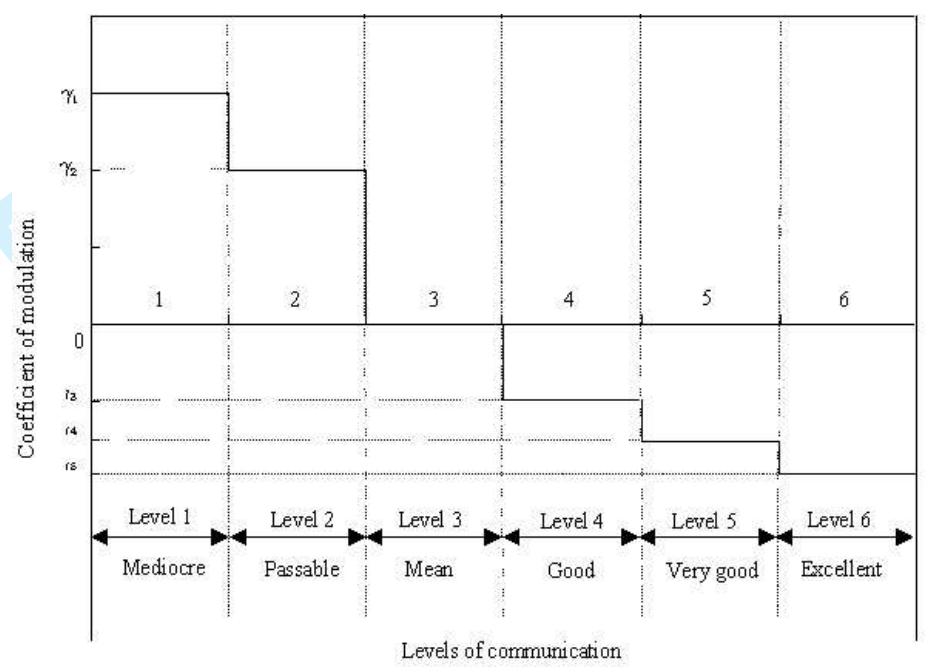

Figure 5 : Modulation coefficient and MC_C relational

The defined laws would only characterize the individual. In a situation, in the presence of teamwork, contextual laws enable aggregation and taking the influence of a set of employees on the performance of an activity into account.

Now that the competence model used and its relation to performance have been presented, the performance estimation method is discussed, while describing the mechanisms proposed to highlight the collective aspect.

\section{Competencies integration method}

\subsection{General method}

For a given activity, the proposed method makes a distinction between the decomposition of nominal performance and the modulation of each of its resulting parts.

1. Decomposition of the nominal performance of an activity:

- Existence of nominal performance

- Segmentation of nominal performance by business domains involved in the implementation of an activity

2. Evaluation of the influence of competencies acquired by human resources on nominal performance: 
- Existence of laws permitting modulation of the estimated performance relative to competencies of actors assigned to an activity

- Considering the collective intrabusiness dimension expressed by contextual laws of an activity, and generally differing from the simple arithmetic average

- Considering the collective interbusiness relational dimension designed to express the positive or negative impact of human character traits on performance

3. Final estimation of an activity performance.

The above-mentioned intrabusiness and interbusiness dimensions, based on the communication parameter, are essentiel. Bidanda (Bidanda et al. 2005) underlined these two aspects. In organization, they make a distinction between vertical (hierarchical) and horizontal (at the same level in the organization) communication. These communication channels can be further divided into intercell (between cell), intracell (within cell), and manager-cell (between management and workers). In the present study, the intercell aspect corresponds to the interbusiness dimension whereas the intracell dimension corresponds to the intrabusiness dimension. Concerning the manager-cell aspect, in a given activity situation, a decision is made by the person at the highest organizational position.

The methodology is now applied to the A2 activity of the process (PAP). The study is focused on its temporal performance.

\subsection{Estimation of an activity performance}

Recall that the basic idea is to quantify the impact of human resource competencies on the nomimal performance of an activity. Contextual laws are used to take the work of the human resources needed to implement an activity into account. These laws determine a coefficient of modulation $\lambda_{A}, \delta_{m}, \gamma_{m k}$ for each competence and business domain-this coefficient allows an activity's nominal performance to be reduced or increased (modulated) according to the competencies of the chosen human resources-.

To clarify the method used to deduce the different weight factors and modulation coefficients, the study focuses on activity A2, and its two corresponding business domains (production and technical) are considered.

Based on the values of the weight factors $P B D_{-} P$ and $P B D_{-} T$ from Table 2, which rely on the importance of the business domains (production and technical), the nominal duration $T_{\text {NOM }}$ of activity A2 can be split into two distincts parts. The first corresponds to a duration linked to the implication of the production domain denoted $T_{N O M_{-} P}$ while taking the weight factor $P B D_{-} P$ 
into account, and the second represents a duration linked to the implication of the technical domain denoted $T_{N_{N} M_{-} T}$ while taking the weight factor $P B D_{-} T$ into account (Equation 1) :

$$
\begin{aligned}
& T_{\mathrm{NOM}_{-} P}=P B D_{-} P \cdot T_{\text {NOM }} \\
& T_{\text {NOM }_{-} T}=P B D_{-} T \cdot T_{\text {NOM }}
\end{aligned}
$$

\subsubsection{Individual performance}

In the example, the production domain only involves a single individual (not a team) (Table 2). The modulation of the duration $T_{N_{O} M_{-} P}$ to characterize the MC_I technicality is estimated as a function of the considered knowledge, behaviour, and know-how. The graph in Figure 3 is thus used to calculate the coefficient of modulation of $\gamma_{P T}$ (Individu) (index [P: production, T: temporal]) of the chosen individual.

Once the nominal duration is modulated, the duration TP associated with the production business domain then becomes (Equation 2):

$$
T P=\gamma_{P T}(\text { Individu }) \cdot T_{N_{O} M_{-} P}+T_{N_{O M} P}=\text { Modulation }+ \text { Nominal Value }
$$

\subsubsection{Intrabusiness collective performance}

Table 2 shows that the technical business domain involves three individuals and two individual main competencies, i.e. MC_I, technicality and decision making.

With regard to the main competence "technicality", the duration $T_{N O M_{-} T T}$ is computed by Equation 3:

$$
T_{N_{-} M_{-} T T}=T D M_{-} T \cdot T_{N_{O M} T}
$$

In this case, using the graph in Figure 5, the coefficient of modulation of the group $\overline{\gamma_{T T}}$ is calculated by averaging the individual coefficients of the group members (Equation 4). This formulation does not favoured some individuals competencies.

$$
\begin{aligned}
& \overline{\gamma_{T T}}=\sum_{n=1}^{n=3} \frac{\gamma_{T T}(\text { Individual })}{n} \\
& n=3 \text { representing the number of individuals of the technical team }
\end{aligned}
$$

The activity duration of the technical domain $T T_{1}$ is then obtained by adding the calculated temporal modulation to $T_{N O M_{-} T T}$ (Equation 5).

$$
T T_{1}=\overline{\gamma_{T T}} \cdot T_{N_{M_{-} T T}}+T_{N_{M_{-} T T}}
$$

The same steps are used to take the main competence decision making into account. First, the 
duration $T_{N O M_{-} T D}$ is estimated, which is given by Equation 6 .

$$
T_{N_{-} M_{-} T}=D D M_{-} D \cdot T_{N O M_{-} T}
$$

In this case, the coefficient of modulation $\gamma_{T D}($ resp $)$ is obtained using the empirical graph presented in Figure 4. This coefficient takes the position and seniority of the group leader of the technical department into account. Here, in the group setting, the individual with the most experience takes (if necessary) the decision making responsability. Hence, the "average" law cannot be used in this case.

The activity duration of the decision making aspect of the technical domain $T T_{2}$ is then given by Equation 7.

$$
T T_{2}=\gamma_{T D}(\operatorname{resp}) \cdot T T_{N_{0 M} T D}+T T_{N^{\prime} M_{-} T D}
$$

The duration of the implementation of activity A2 by the technical department is then obtained by summing the two durations $T T_{1}$ and $T T_{2}$ corresponding to the contribution of the main “technicality and decision making” competencies (Equation 8).

$$
T T_{3}=T T_{1}+T T_{2}
$$

However, the intrabusiness relations have not yet been considered. The relational collective main competence (MC_C) is used for this. This parameter characterizes individuals according to six behavioural levels. The intragroup relations level is then deduced and given by the following equation (Equation 9):

$$
\begin{aligned}
& R_{-j}=E\left(\sum \frac{R(\text { Individu })}{n}\right), \\
& E \quad \text { represents the integer part function } \\
& n=3 \text { represents the number of the individuals in team }
\end{aligned}
$$

This formulation is based on the assumption that within the same business, individuals generally try to limit conflicts. The use of the averaging law appropriately stabilizes a team's relational level. The Integer Part function is also used to measure the penality that can be inflicted on the team, and the relational deficit of one or more of its members.

The relation with the performance is obtained using the empirical graph in Figure 5. The graph gives the coefficient of modulation $\gamma_{R_{G T}}$ of the final duration, associated with a business, according of the estimated relational level $R_{G T}$ of the members of the involved team.

Finally, the coefficient $\gamma_{R_{G T}}$ calculates the duration associated with the technical business domain (Equation 10 ): 


$$
T T=\gamma_{R_{G T}} \cdot T T_{3}+T T_{3}
$$

The total duration $T_{A 2}$, while independently taking the two business domains (production and technical) into account, is estimated by Equation 11:

$$
T_{A 2}=T P+T T
$$

However, the interbusiness aspect must be considered in order to take the cooperation between the technical and production business domains into account.

\subsubsection{Interbusiness collective performance}

The same approach as above is used to express the interbusiness relational aspect. However, in the example, the production department is formed by individuals (not a team), so it is the individual relational level $R_{I P}$ that will be considered. Hence, the interbusiness relational level $R_{M}$ is expressed by Equation 12:

$$
R_{M}=\operatorname{Min}\left(R_{I P}, R_{G T}\right)
$$

This equation is formulated to express the nature of interbusiness relations, which usually differ from intrabusiness relations. Using a "Minimisation" law, suppose that in case of between-team conflicts, these teams will not try to minimize them. This will substantially increase the duration of activity A2. The interbusiness coefficient of modulation is determined via Figure 5. The temporal performance of activity A2 is then evaluated in the same manner for the intrabusiness aspect by Equation 13:

$$
T_{A 2_{-} \text {Finale }}=T_{A 2}+\gamma_{R_{M}} \cdot T_{A 2}
$$

The approach for integration of competencies in the process activity performance computation is now formalized and generalized.

\section{Generalization and formalization of the competencies integration approach}

The previously developed approach will be formalized and explicitly described with regard to the temporal, financial and quality aspects of the performance.

\subsection{Formalization of the competencies integration approach}

The method developed supposes that initially, for a given standpoint, the performance of an activity is characterized by its none zero nominal value $P_{N}$. 


\subsubsection{Computation of business performance}

The nominal performance $P_{N}$ is then decomposed into nominal business performance $P_{N m}$, which takes the involvement of each of the "M" business domains necessary for carrying out an activity into account. A weight factor $\beta_{m}$ represents the relative importance of each business domain in this performance, thus giving rise to the following Equation 13:

$$
\begin{aligned}
& P_{N m}=\beta_{m} \cdot P_{N} \\
& 1 \leq m \leq M
\end{aligned}
$$

The relation between the Nominal Business Performance and the Nominal Performance is thus easily expressed using Equation 14:

$$
P_{N}=\sum_{M} P_{N m}=\sum_{M} \beta_{m} \cdot P_{N} \quad \text { avec } \quad \sum_{M} \beta_{m}=1
$$

Individual competencies are integrated at the business domain level by evaluating the impact of each of the $\mathrm{k}$ competencies relevant to the business domain. Then the nominal business performance by competence $P_{N m k}$ is obtained by Equation 15:

$$
P_{N m k}=\alpha_{m k} . P_{N m} \text { avec } \sum_{k} \alpha_{m k}=1
$$

Laws are then chosen according to the type of activity and to the individual or collective nature of a business so as to determine, for each competence, a coefficient of modulation $\gamma_{m k}$ that takes the influence of the chosen human entities on the performance into account. This method is used to establish the final expression of a business performance by competence $P_{m k}$ (Equation 16):

$$
P_{m k}=P_{N m k}+\gamma_{m k} \cdot P_{N m k}=\left(1+\gamma_{m k}\right) \cdot P_{N m k}
$$

Then the Business Performance could be generally expressed by Equation 17 when the human competencies are integrated.

$$
P_{m}=\sum_{k} P_{m k}=\sum_{k} \alpha_{m k} \cdot\left(1+\gamma_{m k}\right) \cdot P_{N m}=P_{N m} \sum_{k} \alpha_{m k} \cdot\left(1+\gamma_{m k}\right)=\beta_{m} \cdot P_{N} \cdot \sum_{k} \alpha_{m k} \cdot\left(1+\gamma_{m k}\right)
$$

Finally, the relational intrabusiness aspect is taken into account by a single coefficient $\delta_{m}$ for a given business domain. The final expression of Business Performance with Relational $P_{m r}$ is given by Equation 18:

$$
P_{m r}=P_{m}+\delta_{m} \cdot P_{m}=\left(1+\delta_{m}\right) \cdot P_{m}
$$




\subsubsection{Computation of the total performance of an activity}

Now it is possible to express the Performance $P_{A}$ of an activity by summing the expressions $P_{m r}$ derived for each business domain (Equation 19).

$$
P_{A}=\sum_{M} P_{m r}
$$

This expression does not take the impact of interbusiness relations into account. This can be done by introducing of a specific coefficient $\lambda_{A}$ per activity. The Final Performance $P_{F A}$ of an activity can thus be expressed as follows:

$$
P_{F A}=P_{A}+\lambda_{A} \cdot P_{A}=\left(1+\lambda_{A}\right) \cdot P_{A}
$$

Using each of the terms in Equation 20, the formulation developed for the Final Performance of an activity is given by Equation 21:

$$
P_{F A}=\left(1+\lambda_{A}\right) \cdot P_{N} \cdot \sum_{M}\left[\left(1+\delta_{m}\right) \cdot \beta_{m} \cdot \sum_{k} \alpha_{m k} \cdot\left(1+\gamma_{m k}\right)\right]
$$

The above generic formalization, derived expressions, relations and potential constraints can be used to calculate the performance of different activity standpoints (temporal, financial and quality). These latter will now be discussed.

\subsection{Temporal performance}

For this aspect, the activity implementation time is first characterized by its nominal performance $T_{N}$, which is obviously not null. The expression of the final duration of the implementation of an activity can be deduced from Equation 21 by assuming that all the weight and modulation factors have been determined previously for this standpoint. The Final duration of an Activity is expressed by Equation 22 :

$$
T_{F A}=\left(1+\lambda_{T A}\right) \cdot T_{N} \cdot \sum_{M}\left[\left(1+\delta_{T m}\right) \cdot \beta_{T m} \cdot \sum_{k} \alpha_{T m k} \cdot\left(1+\gamma_{T m k}\right)\right]
$$

where $\lambda_{T A}, \delta_{T m}, \beta_{T m}, \alpha_{T m k}, \gamma_{T m k}$ are characteristics of the temporal standpoint T.

\subsection{Financial performance}

From a financial standpoint, the activity is characterized by a Nominal Cost $C_{N}$ which is not null. Equation 23 expresses the Final Cost of an Activity, based on Equation 21, while taking the human dimension into account. 


$$
C_{F A}=\left(1+\lambda_{F A}\right) \cdot C_{N} \cdot \sum_{M}\left[\left(1+\delta_{F m}\right) \beta_{F m} \cdot \sum_{k} \alpha_{F m k} \cdot\left(1+\gamma_{F m k}\right)\right]
$$

where $\lambda_{F A}, \delta_{F m}, \beta_{F m}, \alpha_{F m k}, \gamma_{F k}$ are characteristics of the financial standpoint $\mathrm{F}$.

However, in the case of the financial performance, the cost of an activity can be determined using another method. A first approximation directly tied to the implementation duration and to the hourly costs of the involved resources can be considered. The duration can then be expressed by the Final Duration of an Activity $T_{F A}$ (Equation 22), while the hourly cost can depend essentially on that of the personnel involved in implementing the activity, and on the production tools. Even if there are hidden costs (other financial costs, energy, etc.), the Final Cost of an Activity can reasonably be expressed by Equation 24 .

$$
C_{F A}=T_{F A} \cdot\left(\sum_{j} C_{H j}+C_{\bar{H}}\right)
$$

Where $\mathrm{j}$ represents the number of people involved, $C_{H j}$ the hourly cost of a given involved person, and $C_{\bar{H}}$ the hourly non-human cost (production tools).

$T_{F A}$ can be substituted by its expression :

$$
C_{F A}=T_{N} \cdot\left(1+\lambda_{T A}\right) \cdot \sum_{M}\left[\left(1+\delta_{T M}\right) \cdot \beta_{T M} \cdot \sum_{k} \alpha_{T M k} \cdot\left(1+\gamma_{T M k}\right)\right] \cdot\left(\sum_{j} C_{H j}+C_{\bar{H}}\right)
$$

By identifying the expressions of $C_{F A}$ derived from Equations 23 and 25, it is possible to specifically highlight the relations between the generic method (Equations 23) and the method just outlined (Equations 25). This correlation is achieved via the expression of the coefficients of modulation $\lambda_{T A}, \delta_{T m}, \gamma_{T m k}$ in the following manner:

$$
\begin{aligned}
& \gamma_{F m k}=\frac{\beta_{T m} \cdot \alpha_{T m k} \cdot\left(1+\gamma_{T m k}\right)}{\beta_{T m} \cdot \alpha_{T m k}} \cdot \frac{\left(\sum_{j} C_{H j}+C_{\bar{H}}\right)}{C_{N}}-1 \\
& \delta_{F m}=\delta_{T m} \text { et } \lambda_{F m}=\lambda_{T m}
\end{aligned}
$$

These different expressions show that the coefficients of modulation depend directly on those relative to the temporal standpoint. In particular, Equation 25 shows that is it not necessary to define laws that would modulate the financial performance according of the actors competencies. These laws can be directly deduced from those based on the temporal performance (temporal 
standpoint). The generic approach is not used in the developed method, and the financial cost is obtained via an approach that combines the duration of an activity and the hourly cost of the human and material resources involved.

\subsection{Quality performance}

The activity is characterized by a non-null Nominal Quality $Q_{N}$. Equation 21 can still be formulated, according to the quality standpoint, to express the Final Quality of an Activity $Q_{F A}$ :

$$
Q_{F A}=\left(1+\lambda_{Q A}\right) \cdot Q_{N} \cdot \sum_{M}\left[\left(1+\delta_{Q m}\right) \cdot \beta_{Q m} \cdot \sum_{k} \alpha_{Q m k} \cdot\left(1+\gamma_{Q m k}\right)\right]
$$

where $\lambda_{Q A}, \delta_{Q m}, \beta_{Q m}, \alpha_{Q m k}, \gamma_{Q m k}$ are characteristics of the quality standpoint $\mathrm{Q}$.

However, in this case, the industrial partner insisted on normalizing the quality of an activity and verifying the following double inequation (Merlin Gerin, 2000):

$$
-100 \leq Q_{F A} \leq+100
$$

To address this strong constraint, the following hypothesis are put forward:

- The industrial can specify, at each level of the developed method (activity, business domain, competence), the maximum and minimum limits of direct quality performance that can be achieved,

- The modulation graph form is known but scaled according of the limits set down by the industrial partner at each granularity level.

This reasoning is detailed below and the interbusiness modulation coefficent $\lambda_{Q A}$ will be taken into account.

If the Maximum Quality Performance of an Activity $Q_{A_{\max }}$ (non-relational interbusiness) is defined by the industrial partner, its relation to the Maximum Final Performance of the Activity $Q_{F A_{\max }}$ is given by Equation 30:

$$
Q_{A_{\max }} \cdot\left(1+\lambda_{Q A_{\max }}\right)=Q_{F A_{\max }}=+100
$$

Coefficient $\lambda_{Q A_{\max }}$ represents the possible interbusiness maximum coefficient of modulation.

It is then easy to deduce the value of $\lambda_{Q A_{\max }}$ using Equation 31, which is derived from Equation 
30:

$$
\lambda_{Q A_{\max }}=\frac{100}{Q_{A_{\max }}}-1
$$

In the same manner, the minimal value $\lambda_{Q A_{\min }}$ of the interbusiness aspect can be defined by Equation 32:

$$
\lambda_{Q A_{\min }}=-\left[\frac{100}{Q_{A_{\min }}}+1\right]
$$

These values can be added to the generic modulation graph in order to rescale it. Figure 6 illustrates this mechanism on a curve similar to that used in the previous paragraph to model the Relational MC_C (Figure 5). In this figure, knowledge of the values of $\lambda_{\max }$ and $\lambda_{\min }$, respectively equal to $\lambda_{\mathrm{qAmax}}$ and $\lambda_{\mathrm{qAmin}}$, allows deduction of the values of the intermediary coefficients of modulation $\lambda_{1}$ to $\lambda_{4}$. Then the computed coefficients that take the human entities involved in the activity into account will make it possible to attain a performance of between $[-100,+100]$, as required by the industrial expert.

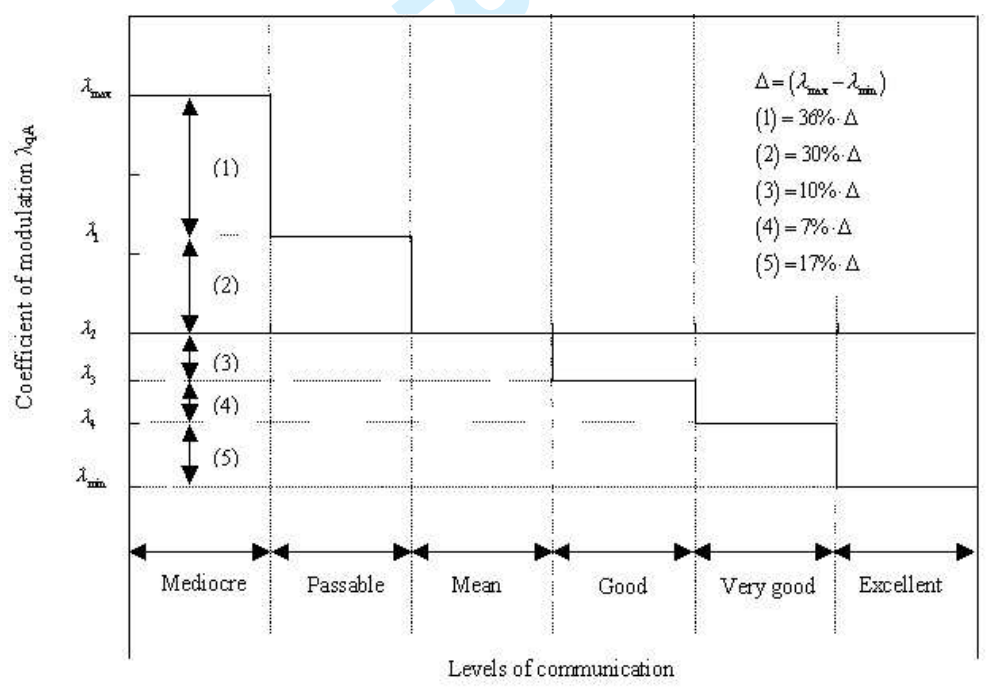

Figure $6:$ Scaling of the coefficient of modulation $\lambda_{\mathrm{qA}}$

This method can be applied for the business domains and competence levels, thus giving Equations 33 and 34:

$$
\delta_{Q m \text { max }}=\frac{Q_{m r \text { max }}}{Q_{m \text { max }}}-1 \text { and } \delta_{Q m \text { min }}=\frac{Q_{m r \text { min }}}{Q_{m \text { min }}}-1
$$


where $\delta_{Q m \text { max }}, Q_{m r \text { max }}, Q_{m \text { max }}$ and $\delta_{Q m \text { min }}, Q_{m r \text { min }}, Q_{m \text { min }}$ are the coefficient of the intrabusiness relational modulation as well as the business performance quality with and without the relational aspect, which are respectively maximum and minimum.

$$
\gamma_{Q m \text { max }}=\frac{Q_{m k \text { max }}}{Q_{N m K}}-1 \text { and } \gamma_{Q m \text { min }}=\frac{Q_{m k \text { min }}}{Q_{N m k}}-1
$$

where $\gamma_{Q m \text { max }}, Q_{m k \text { max }}$ and $\gamma_{Q m \text { min }}, Q_{m k \text { min }}$ are, respectively, the coefficient of modulation of the maximum and minimum performance Quality associated with a competence k. $Q_{N m k}$ represents the Nominal business Performance quality relative to the competence $k$.

When replacing the coefficients $\lambda, \delta$ and $\gamma$ by their maximal and minimal expressions in Equation 28 , the boundary performance values +100 and -100 are actually attained.

\section{Experimentation}

This approach was adopted for the PAP process and led to the development of a set of research studies. The performance of an overall process can be deduced for a given behaviour through estimation of the performance of the activities. The developed model is applied to a small enterprise that employs 24 people who are working in various services. For example, the technical and production services employ three teams, each involving three people with various levels of experience and competence profiles.

\subsection{Estimation of activity performance}

All the described elements can be used to estimate process activity performance. Figure 7 shows, with the temporal aspect, an example of the set of performances in activity A2 of the PAP process for a given group of the actors.

For the chosen configuration, the nominal value of the duration of activity A2 is 1170 minutes. In Figure 7 a large dispersion of the temporal performance is observed according to the individuals selected to carry out activity A2. Although the average duration (1562 minutes) of activity A2 is around the nomimal value, it can vary substantially between 900 to 2600 minutes according to the competence profiles and interbusiness behaviour (relational). 


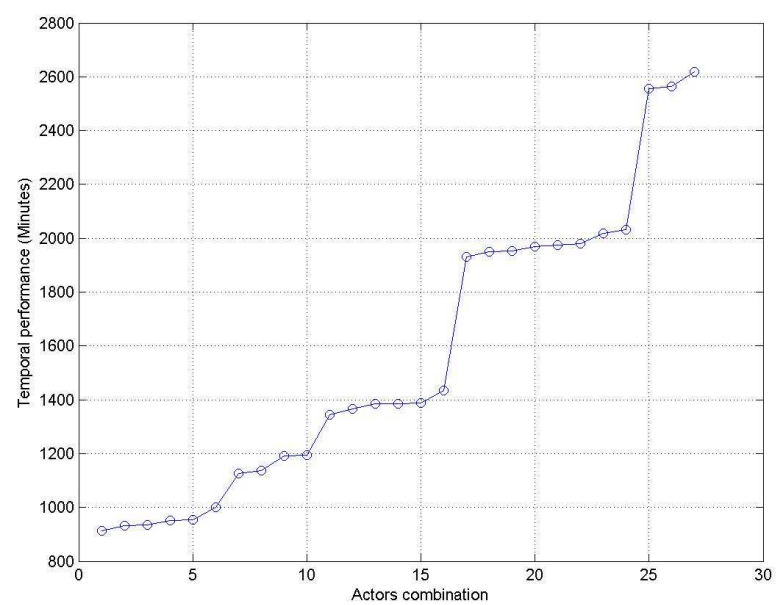

Figure 7. Influence of competencies on the performance of activity A2

The developed performance estimation method links the activity performance to the employees involved. Contrary to industrial schedulers who generally consider the duration of an activity as constant (Grabot and Letouzey 2000). This approach leads to a performance dispersal (for temporal performance) around the nominal value (nominal duration). This was confirmed by the conclusions of an inquiry which showed that almost $70 \%$ of industrial consider that the assigned operators' skills influence the activity duration (Grabot and Letouzey 2000).

\subsection{Estimation of process performance}

The definition of the local performance composition rules, estimated for each activity, is used to compute the global performance of a process for a given partition of human resources (Covès et al. 2000). Figure 8 shows the evolution of the duration of the PAP process for the behavioural sequence $\sigma=\{\mathrm{A} 1, \mathrm{~A} 2, \mathrm{~A} 1, \mathrm{~A} 2, \mathrm{~A} 1, \mathrm{~A} 2, \mathrm{~A} 3\}$, and for a given set of human resources. 


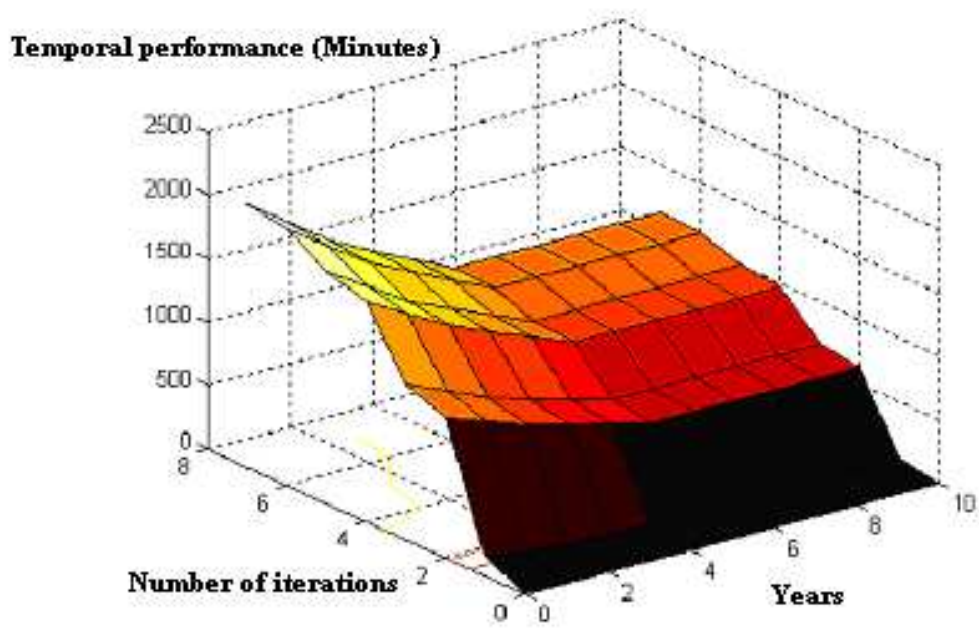

Figure 8 : Temporal performance of the PMP process for a behaviour $\sigma$

The vertical axis corresponds to the estimated temporal performance for each implemented activity during the sequence $\sigma$. Implementation of a behavioural sequence is shown by the depth axis associated with the iteration index. The dynamic evolution of the competencies and then of the temporal performance are shown by the horizontal axis associated to the years. With increased experience, the duration of the implementation of a process decreases and reaches a stable state when all involved actors attain their maximal competence level.

The results of this study allow a user to specifically integrate human competencies when estimating process performance, and it can also be used to guide human resource assignation. Contrary to most previous studies, multiple standpoints concerning industrial process performance can be taken into account. Other studies (Bennour 2004, Bennour et al. 2005) have been focused on determining the set of actors who could meet one or multiple performance goals. An optimum solution of an affectation for a process is not sought and would not be practical. For example, the minimal duration of a process will never be really reached due to unavoidable operational malfunctioning.

\section{Conclusion}

This article highlights several features of competence concepts. Individual, collective, acquired, required, main, knowledge, behaviour and know-how are some of the aspects, thus showing the complexity of the concept. On the basis of these different items, the steps of the proposed method are explained in collaboration with the industrial partner, with the aim of specifically integrating the competence concept in the process activity performance computation. This method distinguishes between individual and collective input and integrates a relational dimension in the presence of work groups. The human entity, however, is not simply reduced to a set of equations. 
Based on the industrial partner's experience, this study only pushed the limits of some previous analysed researches. Although the results are still at the empirical stage, it is clear that there is a real correlation between competence and performance.

In this conclusion, the limits of two aspects are pointed out. The first concerns the modelling of competence, while the second involves the estimation of performance when specifically integrating individual and collective dimensions of human resources involved in the implementation of a process.

The human resource model developed takes several human resource dimensions into account, but it could still be perfected. To integrate individual competencies, other important social parameters should also be assessed, such as motivation and personal ambition. In addition, the collective dimension should be augmented by adding non-relational cohesion factors such as the attraction of collective action and the division of power or leadership. The classification of these different concepts is always feasible. However, the evaluation and the formalization of their relations to the competence stays a more ambitious goal.

The developed performance estimation method also lacks, like other methods. The definition of multiple weight factors is difficult to manage and tends to reduce their impact on performance. Depending on the setting of an activity, only the most relevant competence features should be considered in order to simplify the proposed integration model. However, existing knowledge/competence relations must be formalized in a more rational manner. Many of these relations have been identified, but in the reviewed literature they are generally not formalized. This work could draw on factorial analysis techniques, for example, but this would necessitate substantial investment. A limited study of competencies is not sufficient to deal with the individual aspect, but it would be interesting to evaluate different aspects of individuals' personalities. Some studies have already been undertaken in this direction (Barrick and Mount 1991, Kolbe 1994, Kemble 1996) with the aim of classifying and evaluating individuals on the basis of criteria beyond just their professional competencies. Moreover, modelling individual behaviours in a group would complicate collective aspects evaluation. This dimension was studied by Stevens and Campion (1994) with the aim of evaluating the adequacy of personnel in work groups.

Obviously, it would be virtually impossible to model the human entity in a totally deterministic manner. A fuzzy logic view of human behaviours and competence could be interesting (Boucher and Burlat 2003). However, introducing fuzzy logic (Grocault 2004) in the proposed method induces a maximal dispersion of $10 \%$ of the estimated performance, which does not invalidate results obtained in a deterministic manner. As underlined by C. Lerch (Lerch 1998), the pertinence of an analysis relies more on the quality of its interpretation than on the precision of its 
computations.

These ambitious prospects could only be fulfilled through the development of parallel multidisciplinary studies associating researchers from both the industrial sector and the soft sciences. The industials should strive to quantify competencies and performances, while researchers from the social and human sciences should delineate the limits of a formalization of the human entity and its behaviour in a work setting.

\section{References}

Amice, "CIMOSA: Open Architecture for CIM", Springer Verlag, Berlin, 1993.

Association française de gestion industrielle, Evaluer pour évoluer, les indicateurs de performance au service du pilotage industriel, seminar, 1992.

Arditi, D., Tokdemir, O. B. and Suh, K., Effect of learning on line balancing scheduling, International Journal of Project Management, , 2001, 19, 236-277.

Askin, R. G. and Huang, Y., Forming effective worker teams for cellular manufacturing, International Journal of Production Research, 2001, 39 (11), 2431-2451.

Barrick, M. R. and Mount, M. K., The big five personality dimensions and job performance: a meta-analysis, Personnel Psychology, 1991, 44(1), 1-26.

Becker, G., Investments in human capital: a theoretical analysis, Journal of Political Economy, 1962, 70, 9-44.

Bennour, M., Contribution à l'aide à la décision pour l'affectation des Ressources Humaines aux Processus, PhD Thesis, Université de Montpellier 2, 2004.

Bennour, M., Crestani, D., Crespo, O. and Prunet F., Computer aided decision for human task allocation with mono and multi performance evaluation, International Journal of Production Research IJPR, to be published in 2005.

Berliner, C. and Brimson, J., Cost Management for Todays Advanced Manufacturing: The CAM-I Conceptual Design, 1988 (Harvard Business School Press: USA).

Berrah, L., Une approche d'évaluation de la performance industrielle. Modèle d'indicateur et technique floues pour un pilotage réactif, PhD Thesis,, Institut National Polytechnique de Grenoble INPG, 1997.

Bhaskar, K. and Srinivasan, G., Static and dynamic operator allocation problem in cellular manufacturing systems, International Journal of Production Research, 1997, 35(12), 3467-3481.

Bidanda, B., Ariyawongrat, P., LaScola Needy, K., Norman, B. A. and Tharmmaphornphilas, W., Human related issues in manufacturing cell design, implementation, and operation: a review and survey, Computer \& Industrial Engineering, 2005, 48, 507-523. 
Billionnet, A., Integer programming to schedule a hierarchical workforce with variable demands, European Journal of Operational Research, 1999, 114, 105-114.

Bitton, M., ECOGRAI: Méthode de Conception et d'implantation de Systèmes de Mesures de Performances pour Organisations Industrielles, $\mathrm{PhD}$ Thesis, Université de Bordeaux 1, 1990.

Bobrowski, P. M., Park, P. S., An evaluation of labour assignment rules when workers are not perfectly interchangeable, International Journal of Operation Management, 1993, 11(3), 257-268.

Bonjour, E., Dulmet, M. and Lhote, F., An internal modelling of competency, based on a systemic approach, with socio-technical systems management in view, in Proceeding of IEEE International Conference on Systems, Man and Cybernetics SMC'2002, Hammamet, Tunisie, 2002.

Bonnefous, C. and Courtois, A., Indicateurs de Performance, 2001 (Hermes Science Publication: Paris).

Boucher, X. and Burlat, P., Vers l'intégration des compétences dans le système de performance de l'entreprise, Journal Européen des Systèmes Automatisés, 2003, 37(3), 363-390.

Boucher, X., Cauvin, A. and Kieffer, J. P., The use of skills to support concurrent engineering deployment in the long run, International Journal of Design Sciences and Technology, 2003, 10(1), 31-48.

Boucher, X., Harzallah, M. and Vernadat, F., Articulation entre Compétences et Connaissances en Génie Industriel. in Procceding of Fifth International Industrial Engineering Conference, Quebec, Canada, 2003.

Boucher, X., Cauvin, A. and Kieffer, J. P., Gestion des Compétences dans un Contexte de mise en œuvre de l'Ingénierie Concourante, $3^{\text {ème }}$ Congrès International de Génie Industriel, Montréal, Canada, 1999.

Boucher, E., Legeard, B., Zidoum, H. and Guérineau, G., Utilisation de la PLC ensembliste pour la modélisation et la résolution d'un problème d'affectation, Actes des journées d'affectation et d'ordonnancement du GdR Automatique du CNRS, Tours, 1995, 151-164.

Bourne, M., Implementing performance measurement systems: a literature review, International Journal Business Performance Management, , 2003, 5(1), 1-24.

Bullard, T., Capper, P., Hawes, K., Hill, R. and Tustin, C., The Hunting of the Skills, in Australian and New Zeland Academy of Management Conference (ANZAM '95 Conference), Townsville, Australia, 1995.

Covès, C., Crestani, D., Chapurlat, V. and Prunet, F., Implementation of an approach of performance estimation for enterprise process analysis, in MCPL'2000, 2000, Grenoble, France.

Covès, C., Analyse et Estimation de Performances de Processus d'Entreprise, PhD Thesis, Université de Montpellier 2, 2000. 
Croci, F., Perona, M. and Pozzetti, A., Work-force management in automated assembly systems. International Journal P roduction Economics, 2000, 64, 243-255.

Dejoux, C. and Dherment, I., Incidence de la gestion des compétences professionnelles sur la valeur de l'entreprise, in AIMS, 2000, Montpellier, France.

Dejoux, C., Les compétences aux cœur de l'entreprise, 2001 (Editions d'Organisation: Paris, France).

De Montmollin, M., La compétence dans le contexte du travail, Dans La compétence - Mythe, construction ou réalité ?, 1994 (Editions l'Harmattan: Paris, France).

Donnadieu, P. Denimal, Classification - Qualification: de l'Evaluation des Emplois à la Gestion des Compétences, 1993 (Editions liaisons: Paris).

Dossier Commenté Préparatoire à l'Entretien Annuel d'Appréciation, Merlin Gerin Alès, France, 1997.

Dulmet, M., Bonjour, E., Lhote, F., Mercier, G., Modèle de Caractérisation Interne des Compétences mises en ouvre dans les Entreprises, in $4^{\text {ème }}$ Congrès International de Génie Industriel, Québéc, Canada, 2001, 911-920.

Eckstein, A. L. H. and Rohleder, T. R., Incorporating human resource in group technology/cellular manufacturing, International Journal of Production Research, 1998, 36(5), 1199-1222.

Ehrlich, I., The problem of development: introduction, Journal of Political Economy, 1990, 98(5), Part 2, 1-11.

El Mhamedi, A., Sur l'Intégration des Aspects Humains sur la Conduite Multi-Niveaux d'Ateliers de Production, PhD Thesis, Institut National Polytechnique de Grenoble, France, 1990.

Fallon, P. R., Labour quality and education, in G. Psacharopoulos (Edition) Economics of Education: Resarch and Studies, 1987 (Pergamon Press: Oxford), 116-121.

Franchini, L., Aide à la Décision pour la Gestion des Opérateurs de Production: Modélisation, Planification et Evaluation, PhD Thesis, Institut Nationale Polytechnique de Toulouse, 2000.

Franchini, L., Caillaud, E., Nguyen, P. and Lacoste, G., Workload Control of Human Resources to Improve Production Management, International Journal of Production Research, 2001, 39, 1385-1403.

Gordon, H. and Shaw-Taylor, B., Statistical Process Control, Management Accounting-London, 1996, 74(1), 34-37.

Grabot, B. and Letouzy, A., Short-term manpower management in manufacturing systems: new requirement and DSS prototyping. Computer in Industry, 2000, 43, 11-29.

Guérin, N., Drapeau, C. and Melançon, S., Planification stratégique des ressources humaines. Guide d'accompagnement. 1992 (Vice-présidence à la recherche et au développement, Office des ressources humaines: Québec, Canada). 
Grocaut, N., Intégration des compétences humaines à la méta-modélisation d'un modèle d'entreprise et Estimation de la performance d'un processus par fuzzification. Diplôme d'Etudes Approfondies, Université de Montpellier 2, France, 2004.

Gronalt, M. and Harlt, R. F., Workforce planning and allocation for mid-volume truck manufacturing: a case study, International Journal of production Research, 2003, 41(3), 449-463.

Harzallah, M., Modélisation des Aspects Organisationnels pour la Réorganisation d'Entreprise Industrielles, PhD Thesis, Université de Metz, France, 2000.

Harzallah, M. and Vernadat, F., Human resource competency management in enterprise engineering, in Proceeding of IFAC Word Congress'99, J, Beijing, 1999, 181-186.

Hayes, R. H. and Garvin, D. A., Managing as if tomorrow mattered, Harvard Business Review, 1982, 60(3), 70-79.

Hinds, P. J., Carley, K. M., Krackhardt, D., Wholey, D., Choosing Work Group Members: Balancing Similarity, Competenece and Familiarity, Organizational Behaviour and Human Decision Processes, 2000, 81(2), 226-251.

Jia, T., Vers une meilleure Gestion des Ressources d'un Groupe Autonome de Fabrication, PhD Thesis, Université de Tour, 1998.

Johnston, R. B., The Problem with Planning: The Significance of Theories of Activity for Operations Management, PhD Thesis, School of Business Systems Monash University, 1998.

Johnson, H. T. and Kaplan, R. S., Relevance Lost: the Rise and Fall of ManagementAccounting, , 1987 (Harvard Business School Press: Boston, MA.)

Kaplan, R. S., Accounting lag: the obsolescence of cost accounting systems, California Management Review, Winter, 1986, 18(2), 174-199.

Kaplan, R. and Norton D., The balanced scorecard -measures that drive performance, Harvard Business Review, 1992, 70(1), 71-79.

Kembel, J., ROLE Play — Personalities in Action, 1996 (Life Change Partners), (Northwest Learning Associates, Incorporated: Tucson, Arizona, U.S.A)

Kolbe, K., Pure Instinct, 1994, (New-York: Random house).

Le Boterf, G., De la Compétence: essai sur un attracteur étrange, 1994 (Les Editions d'Organisation: Paris).

Lee, C.-Y., Vairaktarakis, G. L., Workforce planning in mixed model assembly systems, Operational Research, 1997, 45(4), 553-567.

Lerch, C., Une nouvelle représentation du contrôle organisationnel: le pilotage des processus, PhD Thesis, Université Louis Pasteur, Strasbourg, France, 1998.

Lindgren, R., Stenmark, D., Bergquist, M. and Ljungberg, J., Rethinking Competence Systems 
for Innovative Organisations, the 10th European Conference on Information Systems (ECIS), 2001, Bled, Slovenia, 775-786.

Machbach, V., Evaluer et Rénumérer les Compétences, 1999 (Collection Développement et Emplois, Les Editions d'Organisation: Paris).

Maglen, L., Challenging the human capital orthodoxy: the education-productivity link reexamined, The Economic Record, 1990, 66, 281-294.

McEwan, A.M. and Sackett, P., The human factor in CIM systems: worker empowerment and control within a high-volume production environment. Comput. Ind., 1998, Volume 36, Issue 1-2, 39-47.

MEDEF, Les pratiques internationales en matière de compétences, Journées Internationales de la formation, France, Tome 2, 1998.

Merlin Gerin, Dossier commenté préparatoire à l'entretien annuel de compétences, (confidential document), Merlin Gerin Alès, 1997

Merlin Gerin, Analyse des Performances multi-vues et multi-critères de Processus d'entreprise, Covès C., Crestani D., Prunet F., Chapurlat V., Larnac M., Magnier J., Contrat Armines/CNRS N750876/00, "Aide à la modélisation et à l'analyse des aléas de production", contract report, November 2000.

Mosheiov, G., Scheduling problem with learning effect, European Journal of Operational Research, 2001, 13, 687-693.

Mudrack, P. E., Group Cohesiveness and Productivity: a Closer Look, Human Relations, 1989, 42(9), 771-785.

Najar Ben-Mahmoud, L., Méthode de mesure et de pilotage des performances industrielles: une grille d'analyse, in $5^{\text {ème }}$ International Congress of Industrial Engineering, Grenoble, 1996, Tome II, 31-39.

Neely , A.D., Mills J.F., Gregory M.J. and Platts K.W., Performance measurement system design-a literature review and research agenda, International Journal of Operations and Production Management, 1995, 15(4), 80-116.

Nembhard, D. A., Heuristic approach for assigning workers to tasks based on individual learning rates, International Journal of Production Research, 2001, 39(9), 1955-1968.

Norman, B. A., Tharmmaphornphilas, W., Needy K. L.,, Bidanda, B., Warner, R. C., Worker assignment in cellular manufacturing considering technical and human skills, International Journal of production Research, 2002, 40(6), 1479-1492.

Paradeise, C. and Lichtenberger, Y., Compétence, compétences, Sociologie du travail, Editions Elsevier SAS, 2001, 43(1), 33-48.

Pichot, L., Baptiste, P., Ordonnancement des ressources humaines: étude de cas d'une entreprise d'injection plastique, in Actes de la troisième conférence francophone de MOdélisation et SIMulation MOSIM'01, Troyes, France, 2001, 2, 707-714. 
Pourcel, C. and Gourc, D., Présentation de la Méthode MECI, Ecole de Printemps du Groupe Modélisation d'entreprise, 2002, Albi-Carmaux, France.

Saaty, T. L., The Analytical Hierarchy Process, 1980 (McGraw Hill: New-York).

Say, J. B., A Treatise on Political Economy, Translated by Prinsep, C. R. (Traité d'Economie Politique), 1821 (Wells and Lilly: Boston).

Schultz, T., Investment in human capital, American Economic Review, 1961, 51(1), 1-17.

Stevens, M. J. and Campion, M. A., The knowledge, skill, and ability requirements for teamwork: implication for human resource management, Journal of Management, 1994, 20(2), 503530.

Tchommo, J., Baptiste, P. and Soumis, F., Etude bibliographique de l'ordonnancement simultané des moyens de production et des ressources humaines, in Procceding of Fifth International Industrial Engineering Conference, Quebec, Canada, 2003.

Teixeira, A., On the link between human capital and firm performance: A Theoretical and Empirical Survey, Faculdade de Economia do Porto Working Paper, 2002, 121, 1-39.

Wireman, T., Total Productive Maintenance, Seconde Edition, 2004 (Industrial Press Inc.: NewYork, USA.)

Wimmer, M. A., Designing interactive systems: key issues for a holistic approach, PhD Thesis, September, 2000.

Zarifian, P., Le Modèle de la Compétence, 2001 (Collection Entreprise \& Carrières, Editions Liaisons: Paris, France). 